\title{
A IDENTIFICAÇÃO DE PATOLOGIAS EM PONTES DE MADEIRA: DIAGNÓSTICO REALIZADO NO SISTEMA VIÁRIO DO MUNICÍPIO DE PATO BRANCO - PARANÁ
}

\section{IDENTIFICATION OF PATHOLOGIES ON WOODEN BRIDGES OF ROAD SYSTEM: DIAGNOSIS MADE IN THE CITY OF PATO BRANCO - PARANÁ}

\author{
Cleovir José Milani ${ }^{1}$, Moacir Kripka ${ }^{2}$
}

Recebido em 29 de março de 2012; recebido para revisão em 23 de abril de 2012; aceito em 28 de maio de 2012; disponível on-line em 27 de julho de 2012.

\section{PALAVRAS CHAVES: \\ Patologias em construções; \\ Pontes de madeira; Recuperação de pontes de madeira.}

\section{KEYWORDS:}

Buildings pathologies;

Wooden bridges;

Recovery of timber bridges.

\begin{abstract}
RESUMO: O trabalho apresenta a identificação de patologias presentes em pontes de madeira, caracterizando um recorte de levantamento das pontes existentes no município de Pato Branco - Paraná, estudo realizado para identificar os danos mais recorrentes, fornecer subsídios aos administradores, buscando assegurar o correto funcionamento da infraestrutura de transporte e objetivando a preservação do patrimônio público e segurança para o usuário. O método utilizado para as inspeções e vistorias das pontes foi norteado pelas Normas Técnicas 010/2004 - PRO do DNIT e NBR 9452 (1986) da ABNT, com coleta de dados realizada por meio de visitas, utilização do método visual e de registros fotográficos no período de 05 de julho a 15 de outubro de 2009. Os resultados mostram como manifestações patológicas em pontes de madeira, danos por ataque de insetos e ou fungos, vigas em estágio avançado de apodrecimento, defeitos nas peças de madeira do tabuleiro e danos devido a sobrecarga de veículos. A conclusão é de que a maioria dos problemas encontrados pode ser atribuída à inexistência de projetos executivos, falta de mão de obra qualificada para as etapas construtivas e falta de manutenção preventiva, e pelo descumprimento das normas e manuais que orientam a execução e manutenção das pontes.
\end{abstract}

\begin{abstract}
The paper presents the identification of pathologies present in wooden bridges, featuring a collection of cutting bridges in the city of Pato Branco - Parana, a study to identify the most frequent damage, provide support to administrators, seeking to ensure the correct operation of infrastructure transport and in the preservation of public property and safety for the user. The method used for inspections and surveys of the bridges was guided by the Technical Standards 010/2004 - PRO DNIT and NBR 9452 (1986) of ABNT, with data collection performed by means of visits, use of the visual method and the photographic records period from July 5 to October 15, 2009. The results show how pathologies in wooden bridges, damage or attack by insects and fungi, beams at an advanced stage of decay, defects in the wood pieces from the board and damage due to overloading of vehicles. The conclusion is that most of the problems encountered can be attributed to the lack of executive projects, lack of skilled labor for the construction stages and lack of preventive maintenance, and the breach of rules and manuals that guide the implementation and maintenance of bridges.
\end{abstract}

\footnotetext{
* Contato com os autores:

1'e-mail : cjmilani@yahoo.com.br (C. J. Milani)

Engenheiro, Mestre em Engenharia, Professor da Universidade Tecnológica Federal do Paraná - UTFPR.

2e-mail : mkripka@upf.br (M. Kripka)

Doutor na Área de Estruturas, Professor da Universidade de Passo Fundo - UPF.

\section{INTRODUÇÃO}

As pontes são elementos indispensáveis de um sistema viário. Salienta-se que retirar uma ponte de serviço ou restringir a carga máxima aceitável acarreta perturbação no bom andamento do transporte rodoviário ou ferroviário. Como a falta de manutenção das pontes pode ocasionar consequências desastrosas, 
muitos países adotaram medidas para a sua conservação.

As pontes desempenham diversas funções sociais para a sociedade, já que vinculam pessoas e povos. Inclusive, em determinados pontos geográficos interligam até países diferentes, proporcionando o seu desenvolvimento e conectando-os econômica e culturalmente. Consequentemente, construir uma ponte permite alargar as fronteiras nacionais ou até mesmo internacionais.

O sistema rodoviário brasileiro é formado por pontes de diferentes idades, projetadas e dimensionadas segundo diferentes critérios e solicitadas a suportar o tráfego de cargas móveis sempre crescentes, situação que também se verifica no município de Pato Branco - Paraná. Essas obras envelhecidas e degradadas devem ser cuidadosa e regularmente inspecionadas em termos de capacidade de carga, segurança e conforto, com a realização de manutenção e melhoramentos (BRASIL, 2004).

No Brasil, segundo o Departamento Nacional de Infraestrutura de Transporte (DNIT, 2004), a vistoria técnica em pontes já é um trabalho que vem acontecendo periodicamente, possibilitando a recuperação preventiva em estruturas onde foi constatado algum tipo de risco aos usuários. Todavia, em face das carências econômicas, as estruturas excedem a expectativa de vida útil, não recebendo as devidas medidas de manutenção (ALVIM; ALVIM, 2008).

A União, Estados e Municípios brasileiros, em sua absoluta maioria, não adotam procedimentos sistemáticos para inspeções e manutenção das pontes que compõem as suas malhas viárias. Por conta disso, essas obras estão passando por um processo de deterioração cuja evolução ao longo do tempo poderá acarretar a ruína estrutural de significativa parte delas, conforme ficou evidenciado no levantamento dos elementos constituintes de pontes do município de Pato Branco - Paraná.

\section{OBJETIVO}

Realizar levantamento das pontes de madeira existentes no município de Pato Branco visando identificar as manifestações patológicas, para fornecer subsídios aos administradores, buscando assegurar o correto funcionamento da infraestrutura de transporte, com a preservação do patrimônio público e segurança para o usuário.

Efetuar o mapeamento geográfico das pontes de madeira do município de Pato Branco, caracterizando-as em sua estrutura, dimensão e idade, e identificar as principais manifestações patológicas existentes.

\section{METODOLOGIA}

O método utilizado para identificar os danos mais recorrentes das pontes de madeira no município de Pato Branco teve como base a norma de inspeção do DNIT - NORMA 010/2004 - PRO, cuja finalidade é interpretar e avaliar ocorrências danosas detectadas em vistorias, podendo ser visual e instrumental.

A inspeção das pontes de madeira foi conduzida de forma sistemática e ordenada, com inspeção do elemento estrutural em sua totalidade, utilizando-se de fichas de inspeção, documentação fotográfica com enfoque para registro de vista superior, vista inferior, vistas laterais e detalhes de apoio e de articulações.

Para a identificação das pontes foram utilizados recursos do Google Earth e aparelho leitor de coordenadas de Sistema de Posicionamento Global (GPS). As informações coletadas incluíram a localização, a idade, o comprimento, a largura; latitude e longitude, o material de superestrutura e a tipologia da estrutura.

A inspeção realizada de forma visual fundamentou as condições das pontes de madeira em registro fotográfico, identificando-se as possíveis patologias. A coleta de dados em 28 pontes de madeira foi desenvolvida por meio de visitas nas pontes do sistema viário do município de Pato Branco - Paraná no período considerado de 05 de julho a 15 de outubro de 2009.

\section{CONTEXTUALIZAÇÃO}

\subsection{CONCEITOS GERAIS E DEFINIÇÕES PARA PONTES}

$\mathrm{Na}$ acepção técnico/estrutural, pontes são obras de arte que possibilitam a comunicação entre dois pontos separados por um curso de água ou qualquer obstáculo, sendo ainda sujeitas a carregamentos e portadoras de perfeito equilíbrio. Antigamente, os romanos chamavam suas pontes de pedra e madeira de pons (latim), com significado análogo à palavra grega patos e alemã Pfad. De pons originou-se pont em francês, puente em espanhol e ponte em italiano e português. A raiz etimológica da palavra latina é phanthah, que significa imigração, passagem (DEUS, 1997).

O DNIT 010/2004 conceitua ponte desta

forma:

"Estrutura, inclusive apoios, construída sobre uma depressão ou uma obstrução, tais como água, rodovia ou ferrovia, que sustenta uma pista para passagem de veículos e outras cargas móveis, e que tem um vão livre, medido ao longo do eixo da rodovia, de mais de seis metros. Ficam incluídos nesta definição viadutos, passagens superiores $e$ passagens inferiores" (DNIT - NORMA 010/2004 -PRO, p. 3).

Denomina-se, propriamente, ponte quando o obstáculo transposto é um rio. Quando existe um curso de água de grandes dimensões, a ponte necessita de uma parte extensa antes de atravessar o curso de água. Esta parte em seco é denominada de "viaduto de 
acesso". Comumente, chamam-se "pontilhões" as pontes de pequenos vãos, havendo divergência entre os vãos limites dos pontilhões, que alguns engenheiros fixam em cinco metros e outros, em dez metros ou menos. Não há, entretanto, qualquer importância na distinção entre pontes e pontilhões, pois ambos se subordinam aos mesmos procedimentos de projeto e construção (PFEIL, 1990).

Mesmo que os profissionais, arquitetos e engenheiros de cada época acreditassem ter alcançado o limite máximo para projeto e construção de pontes e viadutos e, assim, terem chegado ao ponto culminante dos novos desenvolvimentos, a história tem indicado outra realidade. Atualmente o engenheiro estrutural tem a sua disposição um grande poder de análise, com o uso de programas computacionais, ferramenta que lhe permite desenvolver em minutos o que antes levaria meses ou anos. "Com este ganho de tempo, muitos tipos de pontes têm sido investigadas e outras estão atingindo seu dimensionamento ótimo" (PINHO; BELLEY, 2007, p. 17).

$\mathrm{Na}$ concepção de Pinho e Belley (2007), a eficiência do setor de transportes é certamente um dos requisitos para o desenvolvimento econômico dos países emergentes. Particularmente no que se refere ao transporte rodoviário, é interessante que o país possua uma frota de caminhões moderna, capaz de transportar grandes quantidades de carga sem onerar o custo das mercadorias.
Ferreira (2006) assinala que uma das questões a serem cuidadosamente analisadas é a segurança estrutural das obras de arte existentes na infraestrutura viária: a preocupação com a preservação do patrimônio público advém de alguns estudos que indicam restrições à circulação de veículos considerados nocivos sob o ponto de vista das pontes. Além de órgãos governamentais, o assunto interessa diretamente às concessionárias de rodovias, responsáveis pela manutenção adequada dos trechos sob sua responsabilidade (FERREIRA, 2006, p. 196).

Conforme o autor, a determinação de regras gerais para o peso de veículos de carga encontra obstáculos quando se verifica a existência de diversas classes de pontes, com diferentes idades e sistemas estruturais. Ferreira (2006) ainda argumenta que, mesmo que o poder público tenha recentemente emitido normas que visam garantir a integridade das obras de arte, são necessárias pesquisas que forneçam conhecimento técnico e científico em vista da complexidade do tema. Por fim, o autor salienta que muitas obras de arte apresentam manifestações patológicas que reduzem sua capacidade.

Dessa forma, fazem-se necessárias a inspeção e a manutenção periódicas, além da adequação dos máximos pesos brutos para condições específicas da ponte deteriorada. Na Tabela 1 estão elencadas as principais funções das pontes, já os requisitos fundamentais de uma ponte estão descritos na Tabela 2.

Tabela 1: Principais funções das pontes

Funções principais de uma ponte

1. Funções viárias

A função viária da ponte é, por excelência, dar continuidade à estrada na transposição de um obstáculo. As funções viárias são desempenhadas pelos elementos mais ligados aos usuários.

2. Funções estáticas

A função estática consiste em conduzir as cargas da posição onde elas se encontram até o solo. As funções estáticas são representadas pelos principais elementos estruturais da obra, a saber: lajes, vigamento secundário (longitudinal ou transversal), vigamento principal, pilares, blocos de transição e fundações.

3. Ligação da obra A ligação da ponte com a estrada é feita pelos elementos situados nas extremidades com a estrada da obra, tais como encontros, cortinas, alas laterais, muros auxiliares etc. 
Requisitos fundamentais de uma ponte

1. Funcionalidade

2. Segurança

3. Estética

4. Economia

5. Durabilidade
Quanto à funcionalidade, deverá a ponte satisfazer de forma perfeita as exigências de tráfego, vazão, entre outros.

Quanto à segurança, a ponte deve ter seus materiais constituintes solicitados por esforços que neles provoquem tensões menores que as admissíveis ou que possam provocar ruptura.

Quanto à estética, a ponte deve apresentar aspecto agradável e se harmonizar com o ambiente que se situa.

Quanto à economia, deve-se sempre fazer um estudo comparativo de várias soluções, escolhendo-se a mais econômica, desde que atendidos os itens de funcionalidade, segurança, estética, econômica e durabilidade.

Quanto à durabilidade, a ponte deve atender às exigências de uso durante certo período previsto.

\subsection{ELEMENTOS CONSTITUINTES DAS PONTES}

As pontes, em sua maioria, do ponto de vista funcional, podem ser divididas em três partes principais: infraestrutura, mesoestrutura e superestrutura (PFEIL, 1990; MARCHETTI, 2008), conforme Figura 1.

A infraestrutura é constituída pelos elementos que transmitem diretamente os esforços ao solo (LENCIONI, 2005), que são, os blocos, sapatas, estacas ou tubulões, além das peças de ligação destes elementos, como os blocos de coroamento de conjunto de estacas e vigas de rigidez (SARTORTI, 2008).

$A$ avaliação da correnteza é necessária para dimensionar fundações de pontes. A finalidade da avaliação da correnteza é determinar a suscetibilidade da fundação da ponte para as ações erosivas da água,

Fonte: Adaptado de Marchetti (2008).

que retiram o material de apoio das fundações das pontes. A ponte é considerada crítica se sofrer erosão nas suas fundações. O National Bridge Inspection Standards exige planos de ação detalhados para correntezas críticas.

A mesoestrutura das pontes é constituída pelos pilares, que têm a função de transmitir os esforços da superestrutura para a infraestrutura (fundações). A cada linha transversal de apoio do tabuleiro correspondem um ou mais pilares. Quando são empregados dois ou mais pilares, estes são, normalmente, ligados por vigas horizontais (ou vigas de travamento), formando um pórtico transversal. A escolha do número de pilares e de vigas de travamento depende de diversos fatores, tais como largura do tabuleiro, altura dos pilares, natureza do tráfego, entre outros (ARAUJO, 1999).

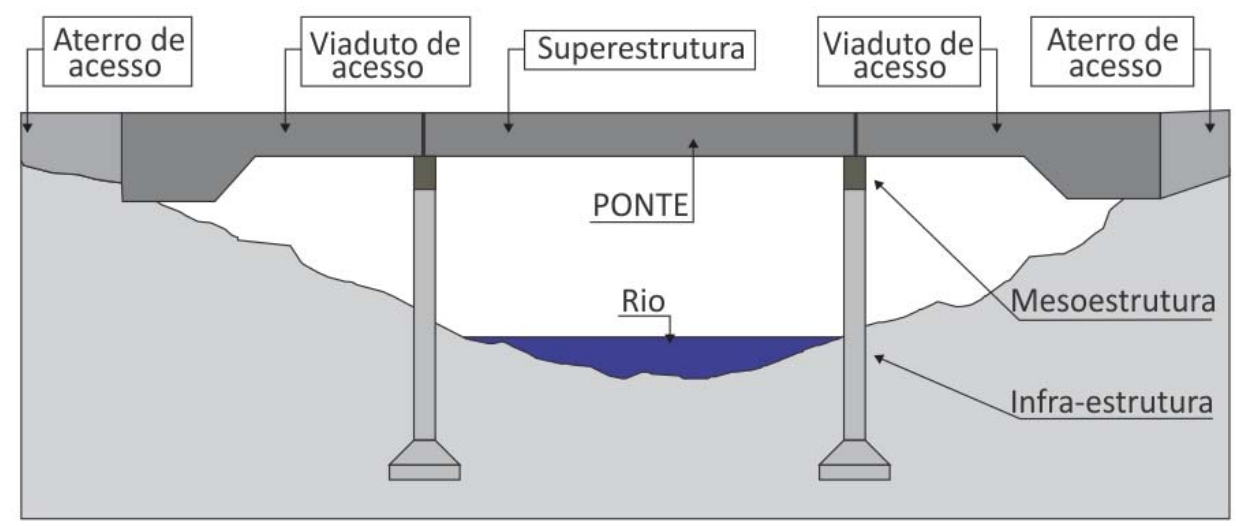

Figura 1: Divisão estrutural de uma ponte.

Fonte: Marchetti (2008). 
A mesoestrutura é composta pelos elementos intermediários, que transmitem os esforços atuantes na pista de rolamento ou tabuleiro aos elementos da fundação. É constituída normalmente por pilares isolados ou aporticados; aparelhos de apoio metálicos ou de borracha e encontros (BRASIL, 1996).

Por superestrutura entende-se a parte da ponte destinada a vencer o obstáculo e receber diretamente as cargas do tráfego, ou seja, é o elemento de suporte do estrado por onde se trafega; assim, é a parte útil da obra. É dividida em estrutura principal (vigas e longarinas) e secundária (tabuleiro ou estrado composto por laje, tábuas ou chapas metálicas). (MENDES, 2003; MARCHETTI, 2008). É constituída basicamente pelos elementos que recebem diretamente a carga útil da ponte.

\subsection{CLASSIFICAÇÃO DAS PONTES}

O critério de classificação das pontes pode ser considerado de diversas maneiras, sendo as mais comuns: quanto à natureza de tráfego; quanto ao material com que são construídas, ao processo construtivo, entre outros:

- extensão do vão (total), Marchetti (2008) classifica as pontes da seguinte forma: vão até 2 m: bueiros; vão de 2 a 10 m: pontilhões; vão maior do que $10 \mathrm{~m}$ : pontes.

- natureza do tráfego, Pfeil (1990) classifica as pontes da seguinte forma: pontes rodoviárias; para pedestres; aquedutos; mistas; ferroviárias; ponte canal e pontes aeroviárias. Podem, ainda, destinar-se ao suporte de tubulações para água, esgoto, gás, óleo.

- vida útil e durabilidade não há como não associar os conceitos vida útil e durabilidade. Conhecidas ou verificadas as características de deterioração dos materiais e dos sistemas estruturais, pode-se entender como durabilidade o parâmetro que relaciona a aplicação destas características a uma determinada construção, individualizando-a pela avaliação da resposta que dará aos efeitos da agressividade ambiental e definindo, assim, a vida útil (SOUZA; RIPPER, 1998).

As exigências de durabilidade constam na NBR 6118 (2003) da ABNT que preconiza que as estruturas de concreto carecem estar projetadas e construídas de modo que, sob as condições ambientais previstas na época do projeto e quando utilizadas conforme preconizado em projeto, conservem sua segurança, estabilidade e aptidão em serviço durante o período correspondente à sua vida útil.

Quanto à vida útil, a NBR 6118 (2003) da ABNT compreende por "vida útil" de projeto o período de tempo durante o qual se mantêm as características das estruturas de concreto sem exigir, em relação às prescrições de manutenção previstas, medidas extras de manutenção e reparo. Assim somente após esse período começa a efetiva deterioração da estrutura, com o aparecimento de sinais visíveis, como produtos de corrosão da armadura, desagregação do concreto, fissuras, entre outros.

Segundo o material da superestrutura, neste trabalho definindo as pontes de maneira, pode se apresentar da forma descrita na sequência. A madeira é considerada um dos materiais de construção mais antigos dada a sua disponibilidade na natureza e sua relativa facilidade de manuseio. Comparada a outros materiais de construção convencionais utilizados atualmente, a madeira apresenta uma excelente relação resistência/peso (PFEIL; PFEIL, 2003).

De acordo com os ensinamentos de Stucchi (2006), a grande vantagem da madeira está na economia quando está disponível, próximo da obra, em qualidade e quantidade aceitáveis. Porém, as desvantagens ficam por conta de dificuldades como durabilidade e resistência ao fogo (bastante diminuídas com os tratamentos modernos), anisotropia e grande variabilidade (reduzidas com as técnicas modernas de construção com pedaços pequenos e classificados de madeira).

Para Stucchi (2006, p. 49), a anisotropia e a não uniformidade caracterizam-se principalmente por: diferença de resistência e rigidez da direção das fibras para a direção normal a elas (resistência cinco vezes menor e rigidez dez vezes menor na normal às fibras); variação das características do eixo para a periferia do tronco (o cerne, próximo do eixo, é muito melhor que o albume, próximo da casca); defeitos da madeira: nós, fendas, furos, curvatura das fibras, entre outras.

As madeiras utilizadas nas pontes podem ser classificadas em maciças (bruta ou roliça, falquejadas e serradas) e industrializadas (compensada, laminada e colada e recomposta) (PFEIL; PFEIL, 2003).

\subsection{PATOLOGIA DAS ESTRUTURAS EM PONTES DE MADEIRA}

Patologia vem a ser a parte da engenharia que estuda os sintomas, os mecanismos, as causas e as origens dos defeitos das obras civis. Em alguns casos tão somente com a visualização é possível estabelecer o diagnóstico das patologias. Em outros, porém, o problema é complexo, sendo necessário verificar o projeto; investigar as cargas a que foi submetida a estrutura; analisar detalhadamente a forma como foi executada a obra e, inclusive, como esta patologia reage diante de determinados estímulos (FERNÁNDEZ CÁNOVAS, 1988).

Machado (2002) destaca que o objetivo principal da patologia das estruturas é encontrar explicações técnicas e científicas para as anomalias encontradas no comportamento das estruturas. Isso pode ocorrer durante a sua construção, em sua fase de serviço, para que se determinem as suas consequências em relação à segurança e à confiabilidade da obra, permitindo que se tome uma decisão correta e segura quanto à utilização posterior das estruturas em análise. 
Levando-se em conta sua duração residual, o objetivo da patologia das estruturas busca definir a conveniência da recuperação, do reforço ou mesmo da demolição pura e simples dos elementos ou da estrutura danificada.

Para que seja completo o diagnóstico das patologias, Machado (2002, p. 5) afirma que é necessário abordar e esclarecer "as manifestações patológicas; os vícios construtivos; as origens dos problemas; os agentes causadores dos problemas; o prognóstico para a terapia, os erros de projeto".

É fato que um diagnóstico adequado será aquele que possibilite esclarecer todos os aspectos do problema, tais como sintomas, mecanismos, origem, causas, consequências e intervenção, terapia, procedimentos.

\subsubsection{Ações e mecanismos de deterioração das estruturas de madeira}

A madeira é um produto privilegiado no Brasil. Trata-se de uma fonte de recursos renovável, quando mantidos programas de controle de extração, reflorestamento, proteção e combate de desastres naturais. Por possuir elevada relação resistência/peso, acaba por favorecer a construção de estruturas mais leves. Além disso, conta com uma alta capacidade de absorção de cargas de curta duração e um baixo custo tecnológico, uma vez que não necessita de equipamentos especiais nem de mão de obra altamente qualificada para a sua construção, permitindo a préfabricação e industrialização (FONTE, 2004).

Callir Junior, Lahr e Dias (2003) consideram a madeira um material adequado para a construção de pontes em estradas vicinais no meio rural para pequenos e médios vãos, não só pela frequente disponibilidade como também pelo seu potencial de resistência e durabilidade, o que a torna economicamente interessante.

Refere Abdalla (2002), muitas pontes de madeira no Brasil têm sido construídas por proprietários de sítios e fazendas, auxiliados pelas prefeituras, para atender às emergências locais, geralmente sem nenhum cálculo estrutural. De fato, os responsáveis por sua edificação são pessoas que não possuem conhecimentos atualizados sobre a madeira e que, na maioria dos casos, desconhecem as características do local onde se dará a construção.

Nota-se, entretanto, que ao longo dos anos, incorretos processos de construção e de manutenção foram empregados na execução de estradas no meio rural, principalmente pela carência de informações técnicas por parte das Administrações Estaduais e Municipais. Com relação às pontes de madeira existentes nestas vias é possível afirmar que não são projetadas e construídas por técnicos e construtores especializados em madeiras. Isto resulta em estruturas caras, inseguras e de baixa durabilidade. O estado atual de degradação destas pontes reflete em um quadro negativo no uso da madeira como um material estrutural (FIORELLI; DIAS, 2008).
Fonte (2004) também concorda que as pontes existentes não foram projetadas e construídas por profissionais especializados em madeira, o que resultou em obras caras, sem segurança e de baixa durabilidade, as quais, na maior parte dos casos, necessitam de reforço estrutural. $O$ estado atual de degradação dessas pontes acaba gerando uma visão negativa da madeira como material de construção.

Percebe-se a necessidade de pontes novas e de recuperação das existentes no Brasil, começando pela esfera municipal até a federal. A construção de rodovias e, por conseguinte, de novas pontes facilita o acesso a lugares com baixa densidade populacional. Também nas regiões populosas ocorre carência de novas pontes, principalmente em vias rurais ou secundárias. Por conta disso, pesquisas de novas tecnologias em madeira, que sejam competitivas, técnica e economicamente, com outros materiais são vitais para reduzir os gastos com essas benfeitorias (CALLIR JUNIOR; LAHR; DIAS, 2003).

\subsubsection{Mecanismos de formação e manifestação das patologias nas estruturas de madeira}

A madeira é um produto biológico sujeito à deterioração pela ação de fungos apodrecedores, insetos xilófagos, perfuradores marinhos, descoloração, agentes químicos, intemperismo e fogo (ABDALLA, 2002).

É fato natural que as obras de madeira apresentem patologias. Verçoza (1991) adverte que a madeira já foi um ser vivo, sendo, por isso, um material orgânico. Dessa forma, em sua maioria, os defeitos nas madeiras são irreversíveis, ou seja, surgindo problemas, não há como fazer correções, apenas remendos. Por conta disso, a solução costumeiramente é substituí-la. Por isso, como em todas as patologias, é preferível prevenir que remediar.

A deterioração da madeira é um processo que altera negativamente as suas propriedades, podendo ser atribuída a duas causas principais: agentes bióticos e agentes abióticos, conforme aponta a Tabela 3.

\subsubsection{Ataque por microrganismos: bactérias e fungos}

Segundo Bauer (1994), os micro-organismos são causadores do apodrecimento e ardidura da madeira. Vivem a expensas de outros organismos vivos na condição de parasitas ou saprófitas, porque estão privados da função clorofiliana para absorção do carbono.

As bactérias são organismos normalmente unicelulares que se reproduzem por cissiparidade; ocasionam tumores que hipertrofiam os tecidos vivos das madeiras (bactérias parasitas), ou originam nos tecidos das madeiras desdobradas complexos fenômenos de decomposição química por oxidação (saprófitas aeróbias) ou redução (saprófitas anaeróbias) (BAUER, 1994).

Gonzaga (2006) caracteriza as bactérias como agentes auxiliares dos fungos com capacidade enzimática de decompor celulose e hemicelulose; rompendo as pontuações (válvulas de passagem da seiva 
entre tecidos), facilitam a penetração das hifas dos fungos apodrecedores.

Os fungos são seres vivos que apresentam um só núcleo, e consomem matéria orgânica (morta fungos saprofíticos, ou viva - fungos parasitários). Em movimentos como os do vento, contato com um animal ou um pequeno impacto, os esporos são liberados do corpo de frutificação e podem ser depositados na superfície de uma peça de madeira (FRIED; HALDEMOS, 2001).

$\mathrm{Na}$ Tabela 4 estão elencados os principais fungos que atacam a madeira.

Os fungos são organismos vegetais (alguns biólogos divergem) rudimentares que não possuem clorofila. Todos requerem certas condições ambientais para seu desenvolvimento:

- umidade - acima de $20 \%$ na madeira;

- temperatura - ideal entre $25 \mathrm{C}^{\circ}$ e $30 \mathrm{C}^{\circ}$; podendo ocorrer acima de $0^{\circ}$ e abaixo de $60 \mathrm{C}^{\circ}$;
- oxigênio - significa aeração, pois não sobrevivem submersos;

- pouca luz solar - não resistem à ação direta dos raios ultravioleta;

- pH levemente ácido (entre 4,5 e 5,5) - não toleram ambiente alcalino ( $\mathrm{pH}$ acima de 7 ).

O conhecimento do tipo climático de uma região fornece indicativos de larga escala sobre as condições médias de pluviosidade e temperatura esperadas. Esse é um primeiro indicativo para se planejar todas as atividades humanas, com atenção especial para a construção de pontes de madeira (IAPAR, 2010).

Os fungos são micro-organismos inferiores, aeróbicos, unicelulares (ficomicetos) ou pluricelulares, que se reproduzem por esporulação. Havendo condições favoráveis ao seu desenvolvimento, o esporo vai se desenvolver e produzir hifas que penetrarão pela estrutura da madeira, fechando assim o seu ciclo vital (BAUER, 1994).

\section{Tabela 3: Agentes bióticos e abióticos}

\section{Agentes bióticos e abióticos que podem estar presentes em uma ponte}

Agentes bióticos

(vivos)

Agentes abióticos

(não vivos)
Os agentes bióticos (vivos) são principalmente os fungos, insetos e furadores marinhos. Estes organismos necessitam de algumas condições para sua sobrevivência, entre elas: temperatura, oxigênio, umidade e fonte adequada de alimento, geralmente a madeira. Embora o grau de dependência destes parâmetros seja variável, cada um precisa estar presente para ocorrer a deterioração.

Os agentes abióticos (não vivos) incluem os condicionantes físicos, mecânicos, químicos e climáticos. Embora destrutivos, os agentes abióticos podem também danificar o tratamento preservativo, expondo a madeira não tratada ao ataque de agentes bióticos.

Tabela 4: Fungos que atuam na madeira

Fungos que atuam na madeira

\begin{tabular}{|c|c|}
\hline $\begin{array}{l}\text { Bolores primários de } \\
\text { hifas hialianas }\end{array}$ & Alimentam-se de açúcares e de resíduos de madeira. \\
\hline Fungos manchadores & $\begin{array}{l}\text { Suas hifas são pigmentadas. Apesar de não comprometerem a estrutura, } \\
\text { diminuem o valor da madeira por mancharem sua superfície. Sob esse aspecto, o } \\
\text { fungo mais comum no Brasil é o que produz a chamada "mancha azul". }\end{array}$ \\
\hline Podridão-mole & $\begin{array}{l}\text { Em geral é provocada por ascomicetos, capazes de degradar celulose e } \\
\text { hemicelulose. Sua ação é relativamente lenta e mais superficial. A peça atacada } \\
\text { apresenta superfície amolecida, com trincas transversais. }\end{array}$ \\
\hline Podridão-parda & $\begin{array}{l}\text { Os principais agentes, os basideomicetos, atacam a celulose, deixando intacta a } \\
\text { lignina. Seu nome vem da cor castanha mais escura que apresentam. A madeira } \\
\text { adquire aspecto de queimado, com rachaduras longitudinais, e suas } \\
\text { características mecânicas entram em colapso. }\end{array}$ \\
\hline Podridão-branca & $\begin{array}{l}\text { No inicio apresentam um aspecto "piolhado" por bolsas brancas na superfície da } \\
\text { madeira. Os principais agentes são os basideomicetos que também degradam } \\
\text { alignina. Pouco a pouco, as pequenas manchas brancas vão se juntando. }\end{array}$ \\
\hline
\end{tabular}




\subsubsection{Infestação de insetos}

A madeira, por ser um material orgânico, está sujeita a ataques por insetos xilófagos que se alimentam de tecido lenhoso e são grandes destruidores de madeira. Suas larvas, durante o desenvolvimento do seu ciclo biológico, alimentam-se da madeira e minam extensas galerias nos tecidos lenhosos. Essas galerias, quando não reduzem perigosamente as seções resistentes das peças em serviço, facilitam a entrada da umidade indispensável ao desenvolvimento de fungos (BAUER, 1994).

Cada família de insetos possui diferenças quanto a características corporais, alimentares ou à fase xilófaga. Na Figura 2 apresentam-se as informações de maior relevância.

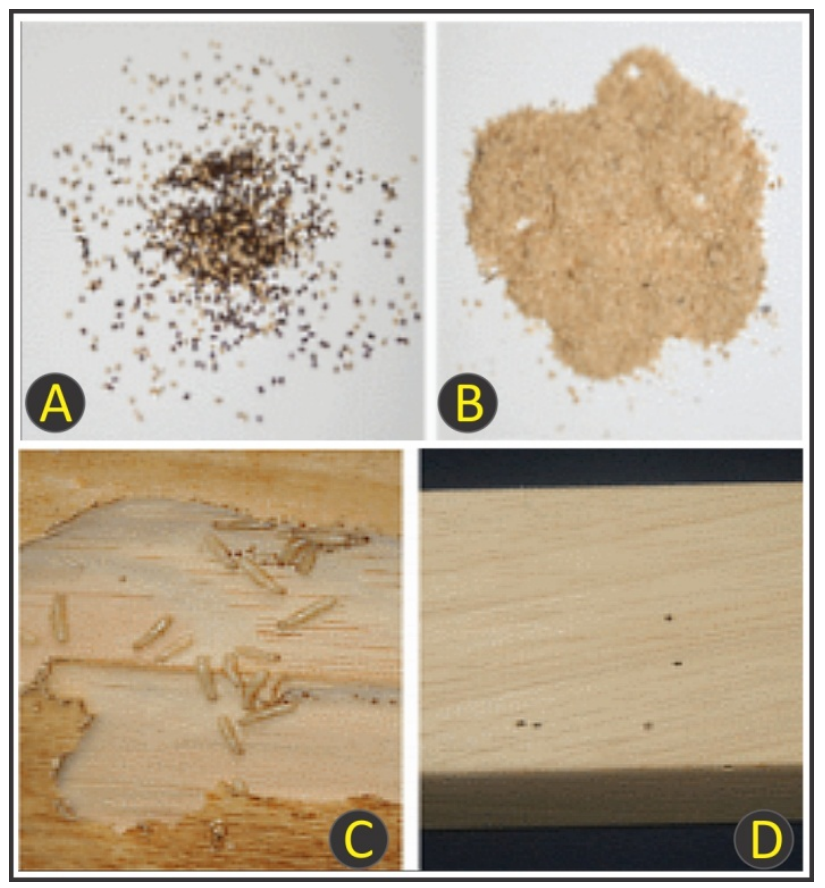

(A) - resíduo de madeira granulado gerado pelo ataque de cupins;

(B) - resíduo de madeira em pó fino produzido por brocas;

(C) - galeria de cupins;

(D) - madeira atacada por brocas.

Figura 2: Manifestações de insetos na madeira.

Fonte: Montana e Química (2009).

Várias espécies de insetos, como cupins e larvas, usam a madeira como abrigo e fonte de alimentação. Neste caso, a alta umidade não é essencial e o risco de infestação é grande. Alguns tipos de ataques de insetos indicam a necessidade do conhecimento de sua extensão, ao passo que outros podem ser menos prejudiciais. Entretanto, a correta identificação é essencial (CALIL JUNIOR, 2006).

As chamadas brocas-de-madeira são besouros que perfuram a madeira em busca de alimento ou abrigo. Diferentemente dos cupins de madeira seca, esses besouros passam por metamorfose completa, apresentando quatro estágios distintos de desenvolvimento: ovo, larva, pupa e adulto.

São as larvas as responsáveis pelos ataques à mobília e a outras peças de madeira. As brocas que atacam a madeira seca, sendo por isso confundidas com cupins, pertencem quase sempre às famílias Anobiidae e Lyctidae. $\mathrm{O}$ ataque por anobídeos produz geralmente um pó mais grosso, enquanto o ataque por lictídeos é facilmente reconhecido pelo resíduo bastante fino, semelhante a talco. O pó-de-broca é constituído apenas de aparas de madeira irregulares (LEONARDO, 2004).

Outras considerações importantes sobre danos nas estruturas de pontes de madeira incluem o movimento de nós e distorções, porquanto as ligações, quando montadas com madeira verde e deixadas para secar, podem resultar em retração, fissuras, distorções ou outras formas de ruptura local. Cavilhas de madeiras duras e entalhes podem partir ou se deslocar. Retração e falta de detalhamento de projeto ou inexistência de conectores não são problemas incomuns em novas estruturas.

Fissuras também são observadas em pontes de madeira, vistas como o resultado da secagem da madeira verde, in loco. Embora preocupantes, as fissuras têm pequena importância estrutural. Em estruturas antigas, podem permanecer presentes por décadas e somente observadas em deslocamentos não estruturais.

Ocasionalmente, se as fissuras são de grande extensão, por exemplo, mais profundas que a metade da espessura da peça; em uma posição crítica em relação aos conectores; ou em uma barra necessitando de proteção ao fogo, os reparos devem ser realizados.

\section{RESULTADOS DO LEVANTAMENTO DIAGNÓSTICO EM PONTES DE MADEIRA DO MUNICÍPIO DE PATO BRANCO - PARANÁ}

No levantamento realizado nas pontes de madeira do Município de Pato Branco - Paraná constatou-se que o modelo estrutural encontrado nas pontes do município de Pato Branco é composto, fundamentalmente, nas pontes de madeira, de vigas de madeira roliça ou falquejadas e, nas pontes de concreto, de vigas e lajes.

A maioria das pontes é formada por pontilhões com menos de 10 metros de comprimento e a maioria absoluta possui extensão abaixo de 20 metros. Já, quanto à idade das pontes, prevaleceram as estruturas com mais de 20 anos, sendo a maioria (18 pontes) entre 26 e 30 anos. Adicionalmente, identificouse 15 pontes com idade presumida entre 36 e 50 anos.

Quanto às pontes de madeira as principais manifestações patológicas observadas visualmente nos elementos da superestrutura foram $93 \%$ com danos na madeira por ataque de insetos e ou fungos, $43 \%$ das pontes de madeira apresentam vigas em estágio avançado de apodrecimento, $82 \%$ com defeitos nas peças de madeira do tabuleiro e $25 \%$ apresentam danos devido a sobrecarga de veículos. Estes índices são mostrados na Figura 3. 


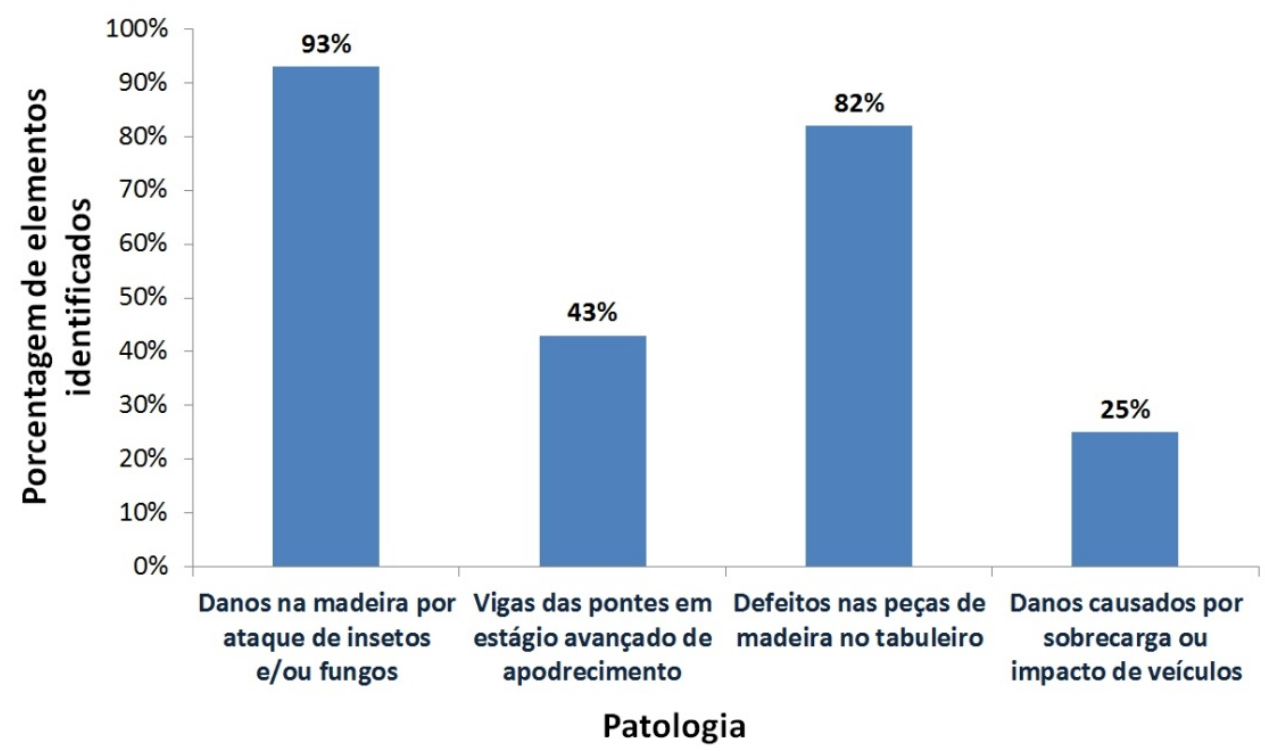

Figura 3: Manifestações patológicas nos elementos da superestrutura das pontes de madeira do município de Pato Branco - Paraná.

O município apresenta dez pontes com apoios das pontes (pilares) construídos com toras de madeira tipo estiva e as principais manifestações patológicas observadas visualmente nos elementos de madeira dos apoios (pilares) das pontes foram $100 \%$ com toras de apoio em estágio avançado de apodrecimento e $100 \%$ aparentam estar com erosão no solo das fundações

Apresentam-se algumas pontes de madeira analisadas, atribuindo uma denominação a fim de facilitar a sintetização de sua patologia e necessidade de inspeção especializada. A Ponte A, mostrada na Figura 4, revela a viga atacada por microrganismos, bactérias e fungos, causadores do apodrecimento da madeira.

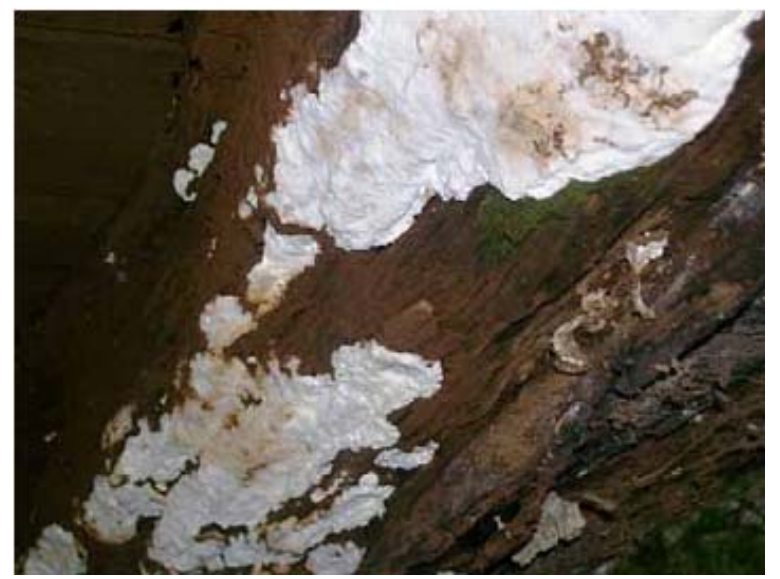

Figura 4: Ataque na madeira por bactérias e fungos na Ponte A.

Nas estruturas de madeira das pontes os fungos encontram condições favoráveis ao seu desenvolvimento, em virtude de fatores propícios, como umidade, temperatura, oxigênio, pouca luz solar.

Na Ponte B, mostrada na Figura 5 percebemse defeitos causados por diversos fatores.

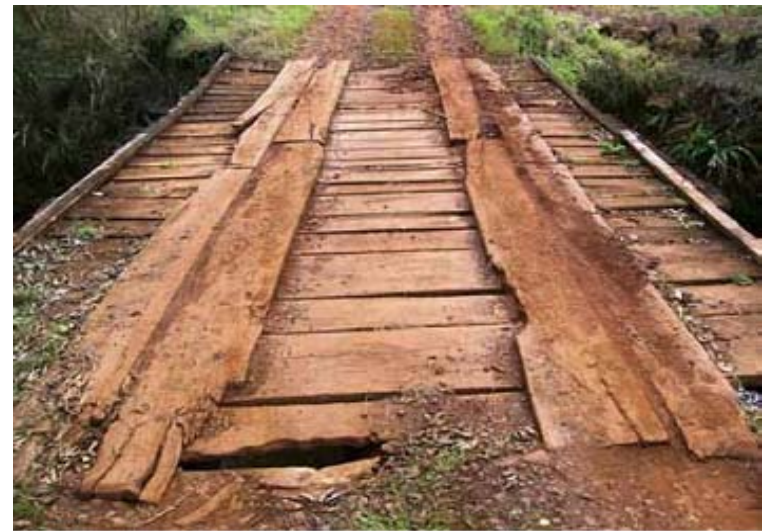

Figura 5: Vista do tabuleiro com indicação de diversos danos na Ponte $\mathrm{B}$.

São característicos os ataques por fungos e insetos, danos no que se refere a sobrecargas, ligação das peças, deslocamentos, fissuras; defeitos na madeira tipo fendas, nós, gretas, abaulamento, arqueamento, empenamento, entre outros.

Observa-se na Ponte $C$, conforme a Figura 6 ataque de insetos nas toras (vigas de sustentação das pontes).

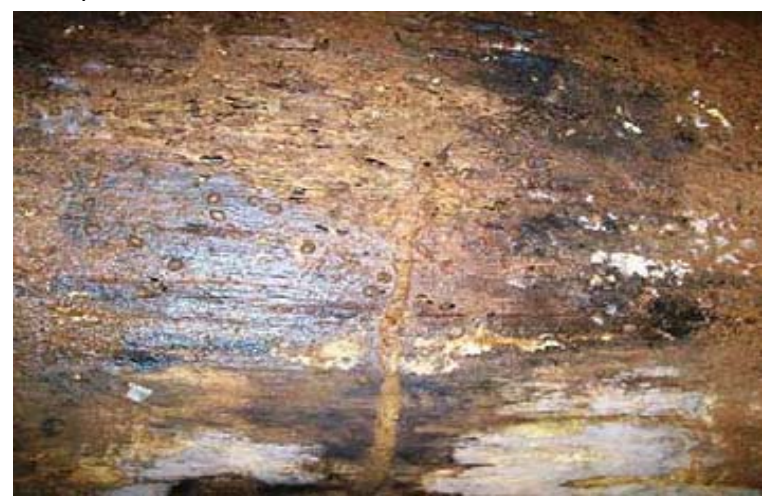

Figura 6: Ataque por insetos nas toras (vigas) de sustentação da Ponte $\mathrm{C}$. 
A madeira sofre ataque por várias espécies de insetos, como cupins e larvas, que usam a madeira como abrigo e fonte de alimentação. Os insetos produzem galerias que reduzem perigosamente as seções resistentes das peças em serviço, facilitando a entrada da umidade, indispensável ao desenvolvimento de fungos.

Na Ponte D, apresentada na Figura 7, percebe-se o apodrecimento da madeira causado pelo ataque de agentes bióticos.

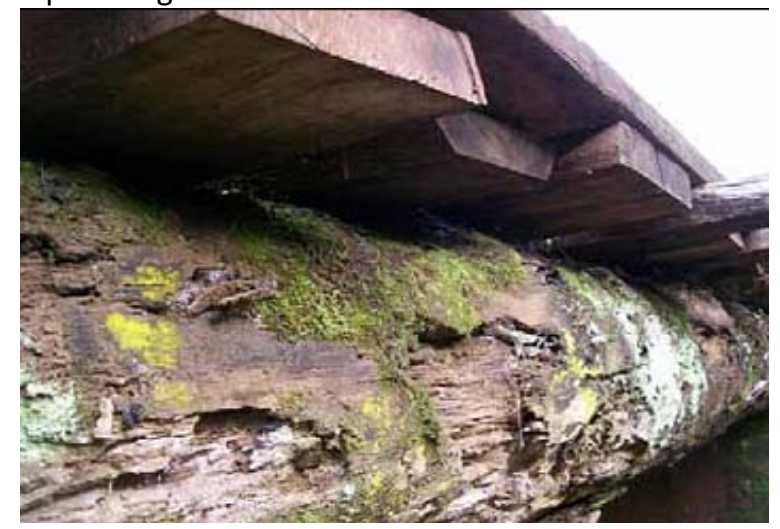

Figura 7: Viga da Ponte D em estágio de apodrecimento.

Da água de chuva que passa pelas frestas das juntas do tabuleiro, parte é retida nas regiões de contato entre as longarinas e transversinas, propiciando uma degradação mais rápida dos elementos da ponte.

Na Ponte E, conforme a Figura 8, verifica-se o estágio avançado de deterioração com rompimento da viga, indicando um colapso iminente.

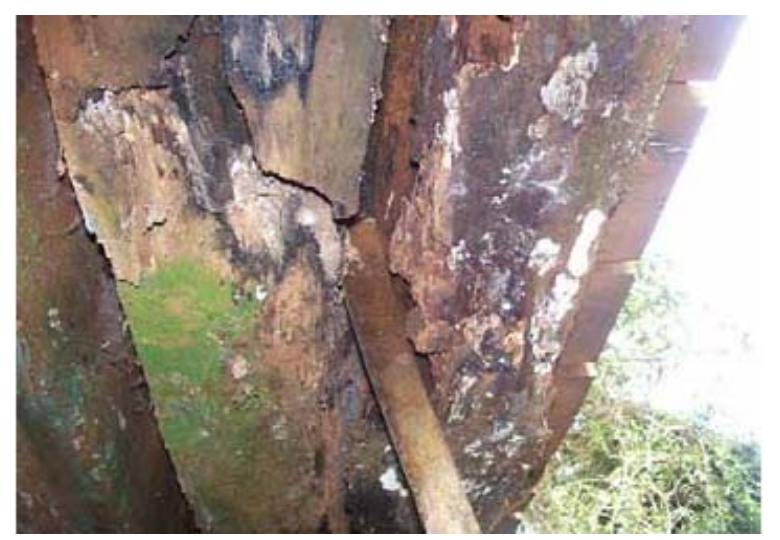

Figura 8: Viga de madeira em estágio avançado de decomposição na Ponte D.

Observa-se na Ponte F, mostrada na Figura 9, um tipo de estrutura denominada genericamente na linguagem dos engenheiros rodoviários de "estiva".

Este tipo de apoio das vigas foi encontrado em $36 \%$ das pontes de madeira analisadas. Destaca-se o avançado estado de apodrecimento das toras de apoio, comprometendo a estabilidade da ponte.

Seguindo a ficha de inspeção cadastral de inscrição as patologias encontradas nas pontes de madeira são apresentadas em suas características e avaliadas quanto à urgência em sua recuperação, conforme Tabela 5.

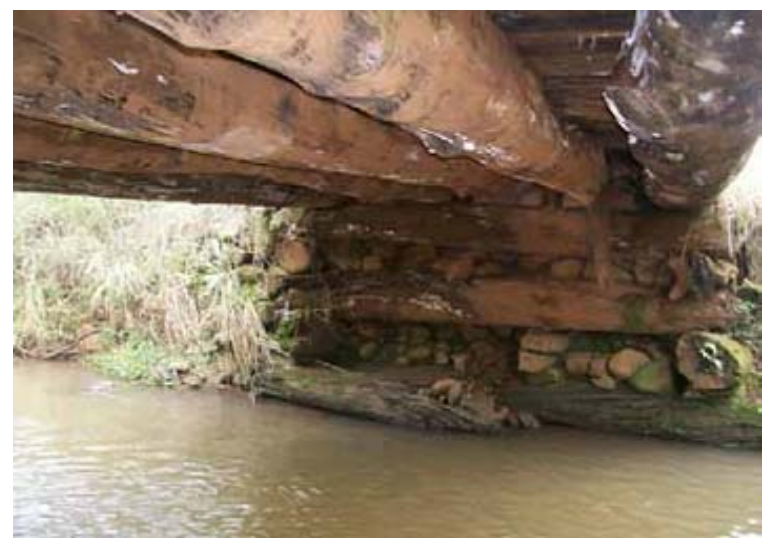

Figura 9: Estiva - Vista de sistema de apoio da Ponte F.

Tabela 5: Patologias encontradas em pontes de madeira e necessidade de inspeção especializada

\begin{tabular}{c|lcc}
$\begin{array}{c}\text { Pontes } \\
\text { analisadas }\end{array}$ & \multicolumn{1}{|c}{$\begin{array}{c}\text { Patologia } \\
\text { detectada }\end{array}$} & $\begin{array}{c}\text { Inspeção } \\
\text { especializada } \\
\text { necessária }\end{array}$ & Urgente \\
\hline Ponte A & $\begin{array}{l}\text { Bactérias e } \\
\text { fungos }\end{array}$ & Não & Não \\
Ponte B & Diversos danos & Sim & Sim \\
Ponte C & $\begin{array}{l}\text { Ataques por } \\
\text { insetos }\end{array}$ & Não & Não \\
Ponte D & Apodrecimento & Sim & Sim \\
Ponte E & Decomposição & Sim & Não \\
Ponte F & Estiva & Sim & Sim \\
\hline
\end{tabular}

Resumindo os dados patológicos nos elementos de superestrutura das 28 pontes de madeira analisadas, as incidências indicam: 26 (92,8\%) das pontes apresentam danos na madeira por ataque de insetos e/ou fungos; 12 (42,8\%) apresentam as vigas em estágio avançado de apodrecimento; 23 (82,1\%) apresentam defeitos nas peças de madeira no tabuleiro, e, $7(25,0 \%)$ apresentam danos causados por sobrecarga ou impacto de veículos.

\section{CONCLUSÃO}

O estudo apresentou, no levantamento das pontes existentes no município de Pato Branco - Paraná, alguns danos mais recorrentes e características das pontes, mediante realização de inspeções e vistorias das pontes fundamentadas nas Normas Técnicas 010/2004 PRO do DNIT e NBR 9452 (1986) da ABNT.

Dos resultados obtidos selecionaram-se para este trabalho as patologias encontradas em pontes de madeira, destacando-se danos na madeira por ataque de insetos e ou fungos, evidente estágio de apodrecimento em vigas, defeitos nas peças de madeira do tabuleiro e danos decorrentes de sobrecarga de veículos.

Acredita-se que os problemas encontrados podem ser atribuídos, na sua maioria, à inexistência de 
projetos executivos, falta de mão de obra qualificada para as etapas construtivas e falta de manutenção preventiva e pelo descumprimento das normas e manuais que orientam a execução e manutenção das pontes.

Presume-se que, pelo fato de a maioria das pontes analisadas se classificarem como pontilhões, não demandando projetos nem controle de execução, os órgãos públicos não Ihes dão a importância merecida, deixando-os abandonados, desconsiderando a segurança do usuário.

\section{REFERÊNCIAS BIBLIOGRÁFICAS}

ABDALLA A. C. P. B. Utilização de madeira de eucalyptus em estruturas de pontes. Dissertação (Mestrado em ciências) - Escola Superior de Agricultura Luiz de Queiroz. Piracicaba, 2002. 108p.

ALVIM, R. de C.; ALVIM, R. de A. A. Metodologia para avaliação do estado de conservação de pontes em concreto armado (2006). Diálogo \& Ciência. Revista da Rede de Ensino FTC. Disponível em: < http://dialogos.ftc.br/index.php?option=com_content\&t ask=view\&id=105\&Itemid=56>. Acesso em: 16 nov. 2008.

ARAUJO, D. L. Projeto de ponte em concreto armado com duas longarinas. Apostila da disciplina Pontes do curso de Engenharia Civil da Universidade Federal de Goiás (1999). Disponível em: <http://www.ctec.ufal.br/ees/disciplinas/ec2/PontePau Seco.pdf>. Acesso em: 03 jun. 2009.

ASSOCIAÇÃO BRASILEIRA DE NORMAS TÉCNICAS. NBR

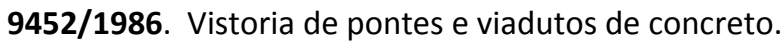

ASSOCIAÇÃO BRASILEIRA DE NORMAS TÉCNICAS. NBR 6118/2003. Projeto e execução de obras de concreto armado.

BAUER, L. A. F. Materiais de construção: novos materiais de construção. 5. ed. , v. 2. Rio de Janeiro: LTC, 1994.

BRASIL. Manual de projeto de obras-de-arte especiais. Rio de Janeiro: Departamento Nacional de Estradas de Rodagem - DNER, 1996.

BRASIL. Manual de inspeção de pontes rodoviárias. 2. ed. Rio de Janeiro: Departamento Nacional de Infraestrutura de Transportes - DNIT, 2004.

BRASIL. Inspeções em pontes e viadutos de concreto armado e protendido - Procedimento. Departamento Nacional de Infraestrutura de Transportes (010/2004 PRO) - Diretoria de Planejamento e Pesquisa/IPR. Disponível em: <http://ipr.dnit.gov.br/normas/DNIT010_2004_PRO.pdf >. Acesso em: 10 out. 2008.
CALIL JUNIOR, C. et al. Manual de projeto e construção de pontes de madeira. São Carlos: Suprema, 2006. $252 p$.

CALIL JUNIOR, C.; LAHR, F. A. R.; DIAS, A. A. Dimensionamento de elementos estruturais de madeira. Barueri: Manole, 2003.

DEUS, E. P. Análise do processo de fraturamento em vigas de pontes de aço sob efeito de fadiga. 1997. Disponível em: <http://www.set.eesc.usp.br/pdf/download/1997DO_En ioPontesdeDeus.PDF >. Acesso em: 15 nov. 2008.

FERNÁNDEZ CÁNOVAS, M. Patologia e terapia do concreto armado. São Paulo: Pini, 1988.

FERREIRA, L. M. Aplicação da teoria da confiabilidade na obtenção de limites para o peso de veículos de carga em pontes de concreto. Tese (Doutorado em Engenharia) - Universidade de São Paulo. São Carlos, 2006.

FIORELLI, J., DIAS, A. A. Levantamento de patologias em pontes de madeira e propostas de recuperação. Ebramen. XI Encontro Brasileiro em madeira e estruturas de madeiras, Londrina, jul. 2010.

FONTE, T. F. Pontes protendidas de eucalipto citriodora. Dissertação (Mestrado em Engenharia) - Universidade de São Paulo. São Carlos, 2004.

FRIED, G.; HALDEMOS, G. Biologia. Portugal: McGrawHill, 2001. 